\title{
Sensitization to Aspergillus fumigatus as a risk factor for bronchiectasis in COPD
}

\author{
This article was published in the following Dove Press journal: \\ International Journal of COPD \\ 31 August 2017 \\ Number of times this article has been viewed
}

\author{
Stephanie Everaerts ${ }^{1,2}$ \\ Katrien Lagrou ${ }^{3,4}$ \\ Adriana Dubbeldam ${ }^{5}$ \\ Natalie Lorent' \\ Kristina Vermeersch ${ }^{2}$ \\ Erna Van Hoeyveld ${ }^{3}$ \\ Xavier Bossuyt ${ }^{3,4}$ \\ Lieven J Dupont ${ }^{1,2}$ \\ Bart M Vanaudenaerde ${ }^{2}$ \\ Wim Janssens ${ }^{1,2}$ \\ 'Department of Respiratory \\ Diseases, University Hospitals \\ Leuven, ${ }^{2}$ Laboratory of Respiratory \\ Diseases, Department of Clinical \\ and Experimental Medicine, $\mathrm{KU}$ \\ Leuven, ${ }^{3}$ Department of Laboratory \\ Medicine, University Hospitals Leuven, \\ ${ }^{4}$ Department of Microbiology and \\ Immunology, KU Leuven, ${ }^{5}$ Department \\ of Radiology, University Hospitals \\ Leuven, Leuven, Belgium
}

Correspondence: Wim Janssens Department of Respiratory Diseases, University Hospitals Leuven,

Herestraat 49, B-3000 Leuven, Belgium

$\mathrm{Tel}+3216346812$

Fax +32 I6 346803

Email wim.janssens@uzleuven.be
Background: Bronchiectasis-chronic obstructive pulmonary disease (COPD) overlap presents a possible clinical phenotype of COPD, but it is unclear why it develops in a subset of patients. We hypothesized that sensitization to Aspergillus fumigatus ( $A$ fum) is associated with bronchiectasis in COPD and occurs more frequently in vitamin D-deficient patients.

Methods: This observational study investigated sensitization to A fum in an outpatient clinical cohort of 300 COPD patients and 50 (ex-) smoking controls. Total IgE, A fum-specific IgE against the crude extract and against the recombinant antigens and $A$ fum $\mathrm{IgG}$ were measured using ImmunoCAP fluoroenzyme immunoassay. Vitamin D was measured by radioimmunoassay, and computed tomography images of the lungs were scored using the modified Reiff score.

Results: Sensitization to A fum occurred in $18 \%$ of COPD patients compared to $4 \%$ of controls $(P=0.0110)$. In all, 31 COPD patients $(10 \%)$ were sensitized to the crude extract and 24 patients $(8 \%)$ had only IgE against recombinant antigens. A fum IgG levels were significantly higher in the COPD group $(P=0.0473)$. Within COPD, $A$ fum-sensitized patients were more often male $(P=0.0293)$ and more often had bronchiectasis $(P=0.0297)$. Pseudomonas aeruginosa and Serratia marcescens were more prevalent in historical sputum samples of $A$ fum-sensitized COPD patients compared to A fum-non-sensitized COPD patients $(P=0.0436)$. Vitamin D levels were comparable $(P=0.2057)$. Multivariate analysis demonstrated that sensitization to recombinant $\mathrm{f} 1$ or $\mathrm{f3}$ had a 2.8 -fold increased risk for bronchiectasis $(P=0.0030)$.

Conclusion: These results highlight a potential role for sensitization to A fum in COPD-related bronchiectasis.

Keywords: Aspergillus fumigatus hypersensitivity, recombinant antigens, ABPA, vitamin D

\section{Background}

Chronic obstructive pulmonary disease (COPD) is highly prevalent and a leading cause of morbidity and mortality worldwide. Both social and economic burden continue to rise. ${ }^{1}$ It has become widely accepted that the degree of airflow limitation is insufficient to estimate the severity and heterogeneity of COPD. Symptoms, exacerbations and comorbidities are well-established determinants. ${ }^{2}$ Furthermore, there is growing interest in phenotyping the disease not only based on clinical characteristics but also on genetic, molecular and cellular parameters. ${ }^{3,4}$ By differentiating phenotypes, a more personalized and effective therapy might be achieved for subgroups of patients.

Jamieson et $\mathrm{al}^{5}$ demonstrated that COPD patients with allergic sensitization experience more symptoms and exacerbations. Although hypersensitivity to Aspergillus fumigatus (A fum) was not measured here, two other studies have reported on the higher prevalence of $A$ fum sensitization in COPD and its association with worse lung function. ${ }^{6,7}$ Sensitization is defined by the presence of allergen-specific IgE, 
which is routinely measured by skin prick test or in vitro immunoassay. In general, a crude extract of $A$ fum is used, although purified or recombinant antigens of $A$ fum are more specific. ${ }^{8}$ Different studies suggest a role for these recombinant antigens in distinguishing patients with and without allergic bronchopulmonary aspergillosis (ABPA) in cystic fibrosis (CF) and asthma. ${ }^{9,10}$ Whether $A$ fum recombinant antigens are also of interest in other lung diseases such as COPD is not known.

COPD-bronchiectasis overlap syndrome is a potential clinical phenotype. ${ }^{11}$ Prevalence varies greatly depending on the definition and methodology. Recent literature shows that bronchiectasis is clinically important ${ }^{12-14}$ and composes an independent risk factor for mortality in COPD. ${ }^{14-16}$ Moreover, diagnosis of bronchiectasis in COPD has an impact on therapeutic considerations such as the safety of inhaled corticosteroids, the need for inhaled antibiotics or maintenance therapy with azithromycin and the antimicrobial management of exacerbations. At present, the pathogenesis of non-CF bronchiectasis is explained by a vicious circle in which inflammation causes structural damage and impaired mucus clearance, which in turn promotes bacterial colonization and infection, again resulting in more inflammation. ${ }^{17}$ The triggers for the development of bronchiectasis in COPD are not known. Given the multiple links between Aspergillus species and bronchiectasis, ${ }^{18}$ we hypothesize that $A$ fum may play an important role in the development of COPD-related bronchiectasis. As A fum sensitization and bronchiectasis may have a common link through suppression of the vitamin D signaling pathway, ${ }^{19-21}$ we also speculate that vitamin $\mathrm{D}$ deficiency, which is frequently observed in COPD and bronchiectasis, ${ }^{22,23}$ may also contribute to $A$ fum sensitization.

We performed an observational study in a COPD cohort and a smoking control group recruited from the outpatient clinic of the University Hospitals of Leuven. We explored if $A$ fum sensitization was more prevalent in COPD patients versus controls by measuring IgE against the crude $A$ fum extract and five commercially available $A$ fum recombinant antigens. We hypothesized that $A$ fum-sensitized COPD patients have different clinical characteristics, lower vitamin $\mathrm{D}$ serum levels and more bronchiectasis compared to COPD patients without $A$ fum sensitization.

\section{Methods}

\section{Study design and subjects}

In this observational study, subjects were retrospectively selected from the Leuven COPD cohort, a DNA, plasma and serum bank of a clinical-based COPD population and controls (NCT00858520). Inclusion criteria were an age of $\geq 50$ years and a smoking history of $\geq 10$ pack-years. A recent diagnosis of cancer, respiratory disorders other than COPD, major thoracic surgery and solid organ transplantation were exclusion criteria. Medical history, clinical parameters, therapy and the modified Medical Research Council (mMRC) breathlessness scale ${ }^{24}$ were surveyed. Exacerbations were defined as acute events with worsening of respiratory symptoms that were beyond normal day-to-day variations and led to a change in medication. ${ }^{2}$ The number of exacerbations in the year prior to inclusion was recorded. The combined assessment as proposed by the Global Initiative for Chronic Obstructive Lung Disease (GOLD) was used to stage the severity of COPD: breathlessness (mMRC) and exacerbation history were used to subdivide COPD patients into four stages; A, B, C and D. ${ }^{2}$ The study was approved by the local ethics committee (Medical Ethical Board of the University Hospitals Leuven, Belgium - ML11081), and all patients provided written informed consent. We selected 300 patients with an established diagnosis of COPD based on a postbronchodilator forced expiratory volume in 1 second $\left(\mathrm{FEV}_{1}\right)$ / forced vital capacity (FVC) ratio $<0.7$, who were included between October 2007 and September 2013. Selection of our study patients was based on Caucasian race, the availability of complete pulmonary function data and $1 \mathrm{~mm}$ thin-sliced computed tomography (CT) imaging of the thorax. The control group consisted of 50 (ex-) smokers with a postbronchodilator $\mathrm{FEV}_{1} / \mathrm{FVC}$ ratio $>0.7$, who were enrolled in a lung cancer screening trial (NELSON, ISRCTN63545820) between October 2007 and October 2009. ${ }^{25}$

\section{Pulmonary function}

Post-bronchodilator spirometry was measured at the time of recruitment using a standardized equipment (Sensormedics Whole Body Plethysmograph; Viasys Healthcare, Vilvoorde, Belgium), according to the American Thoracic Society/European Respiratory Society guidelines. ${ }^{26}$ Diffusion capacity was measured by the single-breath carbon monoxide gas transfer method. ${ }^{27}$ Results are reported as percentages predicted of reference values. COPD was diagnosed based on a post-bronchodilator $\mathrm{FEV}_{1} / \mathrm{FVC}$ ratio of $<0.7$, and the post-bronchodilator $\mathrm{FEV}_{1}$ was used to classify patients according to the GOLD classification. ${ }^{2}$

\section{CT images}

All subjects had a CT of the thorax within 1 year of enrollment. CT scans were taken for a variety of indications, which 
resulted in the use of different protocols in the COPD group. Nevertheless, only patients with slices of $1 \mathrm{~mm}$ were included in this study. Subjects in the control group were all scanned according to the same protocol as described before. ${ }^{25}$ Airway dilatation was determined based on Naidich's descriptions: bronchoarterial ratio $>1$, lack of tapering, presence of bronchus within $1 \mathrm{~cm}$ of costal pleura or abutting the mediastinal pleura. ${ }^{28}$ All scans were blinded to the other data and scored for bronchiectasis using the modified Reiff score. This score ranges from 0 to 18 by assessing the number of involved lobes (the lingula considered separately) and the degree of bronchodilation $(1=$ tubular, $2=$ varicose and $3=$ cystic $) .{ }^{29}$ A score of $\geq 2$ was considered clinically relevant because minor bronchial dilatation is also described in healthy individuals. ${ }^{30}$

\section{Blood analysis}

Plasma was collected in cryotubes and stored at $-80^{\circ} \mathrm{C}$. Total IgE, IgE against $A$ fum extract and against $A$ fum recombinant antigens $\mathrm{f} 1-\mathrm{f} 4$ and $\mathrm{f} 6$ and $A$ fum $\mathrm{IgG}$ were determined by ImmunoCAP fluoroenzyme immunoassay using an ImmunoCAP 1000 instrument (Phadia AB, Uppsala, Sweden). A cutoff of $114 \mathrm{kU} / \mathrm{L}$ was used for total $\mathrm{IgE},{ }^{31}$ and specific IgE values $>0.35 \mathrm{kU} / \mathrm{L}$ were considered positive. We present the specific $\mathrm{IgE}$ results as proportions rather than absolute values due to the detection limit and the clinical relevance. 25-Hydroxy-vitamin D was measured using radioimmunoassay (RIA; DiaSorin, Brussels, Belgium) with results expressed in micrograms per liter.

\section{Sputum}

In the COPD group, the presence of potential pathogenic microorganisms (PPM) in historical sputum cultures was assessed from laboratory reports. All sputum cultures that were performed in our hospital since 2002 were evaluated. These sputum samples were mainly collected during bronchitis or exacerbation episodes. We registered if they ever had PPM cultured, and if so, which different species were found. All cultures were performed according to the standard protocol of our hospital. In brief, $10 \mu \mathrm{L}$ of sputum sample was inoculated on four different agars: blood agar, Haemophilusspecific agar, mannitol salt agar and MacConkey agar. These were cultured for 2 days.

\section{Statistical analysis}

Statistical analysis was performed with GraphPad Prism 4 (GraphPad Software, Inc., La Jolla, CA, USA) and SAS software version 9.4 (SAS Institute Inc., Cary, NC, USA). Normality was tested by the Shapiro-Wilk test; none of the continuous variables were normally distributed. Univariate comparisons between groups were performed by Wilcoxon rank-sum test and presented as median \pm interquartile range (IQR). Proportions of discrete variables were compared with $\chi^{2}$ test and presented as absolute numbers and percentages. We built a multivariate logistic regression model to study the association between sensitization to A fum recombinant $\mathrm{f1}$ (rAsp f1) or A fum recombinant f3 (rAsp f3) and bronchiectasis in COPD. After performing bivariable logistic regression models with modified Reiff score $\geq 2$ as exposure, potential confounders of the association between sensitization and the presence of bronchiectasis were included in the final model if they 1) changed the estimate of the multivariable model $\geq 10 \%$ or 2 ) the variable was significantly associated with the presence of bronchiectasis. $P$-values $<0.05$ were considered significant in all analyses.

\section{Results Study group characteristics}

A total of 350 subjects were included in this study: 300 patients with COPD and 50 (ex-) smoking controls. There was no difference in gender. Patients in the COPD group were older, smoked more and had a lower mean body mass index (BMI) than controls (Table 1). The COPD group had a median $\mathrm{FEV}_{1}$ of $43 \%$ predicted and a median diffusion capacity of $46 \%$ predicted. The majority of COPD patients were staged in GOLD classes 2 and 3 or groups B and D. ${ }^{32}$

Table I Study group characteristics

\begin{tabular}{|c|c|c|c|}
\hline Characteristic & Control & COPD & $P$-values \\
\hline Patients (n) & 50 & 300 & \\
\hline Men (\%) & $37(74.0)$ & $215(71.7)$ & 0.7337 \\
\hline Age, years & $62(58-68)$ & $67(6 \mathrm{I}-74)$ & 0.0002 \\
\hline Pack-years & $35.5(26.8-46.8)$ & $48.9(34.0-64.1)$ & 0.0001 \\
\hline Current smokers (\%) & $26(52)$ & $125(42)$ & $0.178 \mid$ \\
\hline BMI, kg/m² & $27.3(23.9-29.4)$ & $24.1(20.7-27.5)$ & 0.0004 \\
\hline $\mathrm{FEV}_{1}, \mathrm{~L}$ & $2.9(2.4-3.4)$ & $1.2(0.9-1.6)$ & NA \\
\hline $\mathrm{FEV}_{1}$, \% pred & 104 (92-III) & $43(34-58)$ & NA \\
\hline $\mathrm{DL}, \mathrm{co}, \mathrm{mmol} / \mathrm{min} / \mathrm{Kpa}$ & $7.5(6.1-8.9)$ & $3.8(3.0-5.0)$ & NA \\
\hline DL,co, \% pred & $83(78-94)$ & $46(36-58)$ & NA \\
\hline GOLD I/2/3/4, \% & NA & $5.7 / 32.0 / 45.7 / 16.7$ & NA \\
\hline GOLD assessment & NA & $4.0 / 21.3 / 5.3 / 69.3$ & NA \\
\hline \multicolumn{4}{|l|}{$\mathrm{A} / \mathrm{B} / \mathrm{C} / \mathrm{D}, \%$} \\
\hline Vitamin $D, \mu g / L$ & $28.5(21.2-35.5)$ & $17.3(12.4-23.1)^{\mathrm{a}}$ & $<0.0001$ \\
\hline $\begin{array}{l}\text { Modified Reiff } \\
\text { score } \geq 2 \text { (\%) }\end{array}$ & $5(10)$ & $99(33)$ & 0.0010 \\
\hline
\end{tabular}

Notes: Data are presented as n, $\mathrm{n}(\%)$, median (interquartile range) or \%. ${ }^{\mathrm{a} B a s e d}$ on 240 COPD patients after exclusion of subjects taking vitamin D supplements. $P$-values $<0.05$ are shown in bold.

Abbreviations: COPD, chronic obstructive pulmonary disease; BMI, body mass index; $\mathrm{FEV}_{1}$, forced expiratory volume in I second; \% pred, percentage predicted; DL,co, diffusion capacity of the lung for carbon monoxide; GOLD, Global Initiative for Chronic Obstructive Lung Disease; NA, not applicable. 
Table 2 Total IgE and A fum-specific antibodies

\begin{tabular}{|c|c|c|c|}
\hline Variables & Control & COPD & P-values \\
\hline Patients (n) & 50 & 300 & \\
\hline Total IgE, kU/L & $42.5(16.5-105.5)$ & $52.0(17.0-198.5)$ & 0.3068 \\
\hline $\begin{array}{l}\text { Total IgE > I I4, } \\
\text { kU/L (\%) }\end{array}$ & I I (22) & $103(34.3)$ & 0.0849 \\
\hline A fum extract IgE (\%) & I (2) & $31(10.3)$ & 0.0584 \\
\hline rAsp fl IgE (\%) & I (2) & $36(12)$ & 0.0332 \\
\hline rAsp f2 IgE (\%) & I (2) & $7(2)$ & 0.8839 \\
\hline rAsp f3 IgE (\%) & I (2) & $20(6.7)$ & 0.1983 \\
\hline rAsp f4 IgE (\%) & $0(0)$ & $3(1)$ & 0.4776 \\
\hline rAsp f6 lgE (\%) & $0(0)$ & $4(1.3)$ & 0.4115 \\
\hline Sensitized in total $(\%)^{\mathrm{a}}$ & $2(4)$ & $55(18.3)$ & 0.0110 \\
\hline A fum $\mathrm{lgG}, \mathrm{mg} / \mathrm{L}$ & $20.7(9.6-42.8)$ & $31.0(15.9-48.5)$ & 0.0473 \\
\hline
\end{tabular}

Notes: Data are presented as $\mathrm{n}$, median (interquartile range) or $\mathrm{n}(\%) . P$-values $<0.05$ are shown in bold. aSensitization to at least one of the $A$ fum allergens including the extract.

Abbreviations: COPD, chronic obstructive pulmonary disease; $A$ fum, Aspergillus fumigatus; $\mathrm{rAsp} \mathrm{fl}, \mathrm{A}$ fum recombinant $\mathrm{fl}$; $r$ ssp $\mathrm{f} 2, A$ fum recombinant $\mathrm{f} 2$; $\mathrm{rAsp} \mathrm{f} 3, A$ fum recombinant $\mathrm{f3}$; $\mathrm{rAsp} f 4, A$ fum recombinant $\mathrm{f4}$; $\mathrm{rAsp} \mathrm{f6}, \mathrm{A}$ fum recombinant $\mathrm{f6}$.

In vitamin D non-supplemented COPD patients $(\mathrm{n}=240)$, a significantly lower median vitamin D level was observed compared to the control group (17.3 versus $28.5 \mu \mathrm{g} / \mathrm{L}$, $P<0.0001)$. The proportion of subjects with bronchiectasis was higher in the COPD group compared to controls $(33 \%$ versus $10 \%, P=0.0010$ ). More detailed information about the study groups is given in Table 1.

\section{Total IgE and $A$ fum-specific antibodies}

Total IgE, A fum-specific IgE against the crude extract and the recombinants and $A$ fum-specific IgG were measured to determine antibody production against $A$ fum. Details of these results are given in Table 2 . There was a tendency to higher total IgE levels and more prevalent IgE against $A$ fum extract in COPD patients compared to controls (Figure 1A and B). If recombinant antigens were considered, significantly more COPD patients than controls had IgE against rAsp f1 $(12 \%$ versus $2 \%, P=0.0332$; Figure $1 \mathrm{~B})$. Sensitization to $A$ fum extract and rAsp f1 occurred in different patients: out of 50 patients sensitized to one of these two allergens, only 17 patients developed IgE antibodies $>0.35 \mathrm{kU} / \mathrm{L}$ against both $A$ fum extract and rAsp f1 (Table 3). IgEs against $A$ fum recombinant $\mathrm{f} 2$ (rAsp f2), A fum recombinant $\mathrm{f} 4$ (rAsp f4) and $A$ fum recombinant f6 (rAsp f6) were only rarely present in both groups, while there was no significant difference in IgE against rAsp f3 (Figure 1B). The difference in sensitization to at least one of the tested allergens was statistically significant: 55 (18.3\%) COPD patients versus two (4\%) controls, $P=0.0110$ (Figure 1B). Furthermore, COPD patients had a higher median level of $A$ fum $\mathrm{IgG}$ (31 versus $20.7 \mathrm{mg} / \mathrm{L}, P=0.0473$; Figure 1C).

\section{Differences between sensitized and non- sensitized COPD patients}

Clinical and demographic characteristics were compared between 55 A fum-sensitized COPD patients and 245 A fum-non-sensitized COPD patients. In the sensitized group, the proportion of men was significantly higher $(83.6 \%$ versus $69 \%, P=0.0293$ ). There was no difference in age,
A

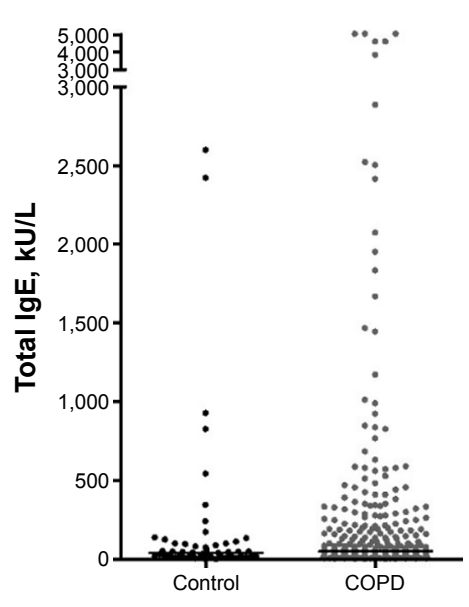

B

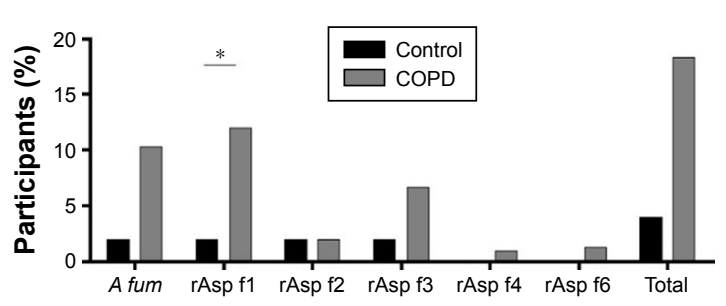

C

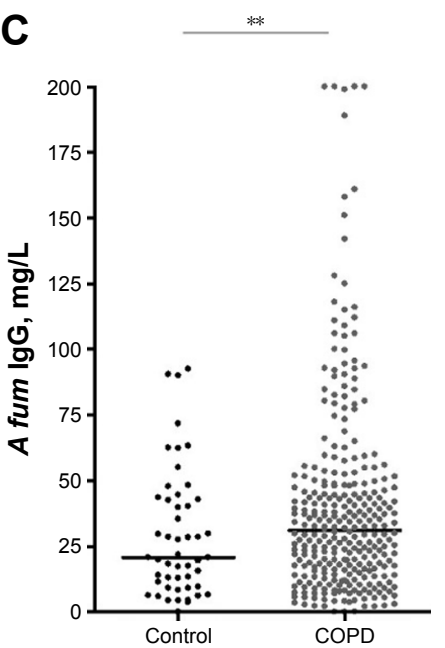

Figure I Total lgE and A fum-specific antibodies in patients with COPD versus controls.

Notes: Antibody levels were measured in plasma by ImmunoCAP fluoroenzyme immunoassay using an ImmunoCAP 1000 instrument (Phadia AB, UPpsala, Sweden). (A) Median values of total lgE. No significant difference between controls and COPD, $P=0.3068$. (B) Proportions of subjects with lgE against different $A$ fum allergens: extract of $A$ fum, $A$ fum recombinant $\mathrm{fl}$ ( $\mathrm{rAsp} \mathrm{fl}$ ), A fum recombinant $\mathrm{f} 2$ ( $\mathrm{rAsp} \mathrm{f} 2$ ), A fum recombinant $\mathrm{f} 3$ ( $\mathrm{rAsp} \mathrm{f} 3$ ), $A$ fum recombinant $\mathrm{f4}$ ( $\mathrm{rAsp} \mathrm{f4}$ ) and $\mathrm{A}$ fum recombinant $\mathrm{f6}$ ( $\mathrm{rAsp} \mathrm{f6}$ ). Total shows the proportion of participants sensitized against at least one of the tested allergens $(* P<0.05)$. (C) Median values of $A$ fum-specific lgG. Difference between COPD and control was significant ( $* * P=0.0473)$.

Abbreviations: COPD, chronic obstructive pulmonary disease; $A$ fum, Aspergillus fumigatus; $\mathrm{rAsp} f \mathrm{fl}, \mathrm{A}$ fum recombinant $\mathrm{fl}$; $\mathrm{rAsp} \mathrm{f} 2, \mathrm{~A}$ fum recombinant $\mathrm{f2}$; $\mathrm{rAsp} \mathrm{f} 3, \mathrm{~A}$ fum recombinant $\mathrm{f} 3$; rAsp f4, A fum recombinant $\mathrm{f4}$; $r$ Asp f6, $A$ fum recombinant $\mathrm{f6}$. 
Table $3 \mathrm{lgE}$ against $A$ fum extract and $\mathrm{rAsp} \mathrm{fl}$ in a contingency table

\begin{tabular}{|l|l|l|l|}
\hline & $\begin{array}{l}\text { rAsp fI IgE } \\
\text { present }\end{array}$ & $\begin{array}{l}\text { rAsp fI IgE } \\
\text { absent }\end{array}$ & Row total \\
\hline $\begin{array}{l}\text { A fum extract } \\
\text { IgE present }\end{array}$ & $17(7.5)$ & $14(4.7)$ & $3 I(I 0.3)$ \\
\hline $\begin{array}{l}\text { A fum extract } \\
\text { IgE absent }\end{array}$ & $19(6.3)$ & $250(83.3)$ & $269(89.7)$ \\
\hline Column total & $36(12.0)$ & $264(88.0)$ & $300(100)$ \\
\hline
\end{tabular}

Note: Data are presented as $\mathrm{n}(\%)$.

Abbreviations: A fum, Aspergillus fumigatus; $r$ Asp $\mathrm{fl}$, A fum recombinant $\mathrm{fl}$.

BMI, smoking history and use of inhaled corticosteroids. Furthermore, lung functional variables and GOLD stages were not different and sensitized patients did not experience more exacerbations compared to non-sensitized patients. Vitamin D levels were comparable in the sensitized versus non-sensitized COPD patients (16.2 versus $18.1 \mathrm{ng} / \mathrm{mL}$, $P=0.2057)$. However, median values of specific $A$ fum IgG were higher in $A$ fum-sensitized patients (43.2 versus $27.7 \mathrm{mg} / \mathrm{L}, P<0.0001$ ), who also had significantly more bronchiectasis compared to non-sensitized patients (45.5\% versus $30.2 \%, P=0.0297)$. Data are presented in Table 4 .

Interestingly, bronchiectasis was only detected in patients with sensitization to recombinants. None of the nine patients who were only sensitized to the crude extract - and therefore not to any of the recombinant allergens - had bronchiectasis. In contrast, patients with IgE against rAsp f1, and especially against rAsp f3, had significantly more bronchiectasis than patients without sensitization to these allergens (Table 5).

Results of sputum cultures were available in 197 patients. The median number of sputum samples per patient was not different between groups (4 [IQR 2-6] in sensitized patients and 3 [IQR 1-5] in non-sensitized patients, $P=0.0692$ ). PPM were significantly more prevalent in $A$ fum-sensitized versus A fum-non-sensitized patients $(76.9 \%$ versus $59.5 \%$, $P=0.0436$; Table 4). Sputum cultures showed no difference in the presence of typical COPD pathogens like Streptococcus pneumonia, Haemophilus influenza and Moraxella catarrhalis. In contrast, Pseudomonas aeruginosa and Serratia marcescens were more common in sputum cultures of A fum-sensitized patients (Figure 2).

Multivariate analysis with logistic regression showed a significant association between bronchiectasis, sensitization to rAsp f1 or rAsp f3 $(P=0.0030)$ and age in COPD, independent of gender, BMI, diffusion capacity and presence of $\geq 2$ exacerbations/year (Table 6). This significant association between $\mathrm{rAsp} \mathrm{f1}$ or rAsp $\mathrm{f3}$ sensitization and bronchiectasis was confirmed with the same model in the subgroup of patients with sputum samples ( $\mathrm{n}=197, P=0.0021$ ), additionally corrected for the presence of PPM (Table 6).

Table 4 A fum-sensitized COPD patients versus $A$ fum-non-sensitized COPD patients

\begin{tabular}{|c|c|c|c|}
\hline Characteristic & $\begin{array}{l}\text { COPD patients } \\
\text { non-sensitized to } A \text { fum }\end{array}$ & $\begin{array}{l}\text { COPD patients } \\
\text { sensitized to } A \text { fum }\end{array}$ & $P$-values \\
\hline Patients (\%) & $245(81.7)$ & $55(18.3)$ & \\
\hline Men (\%) & $169(69.0)$ & $46(83.6)$ & 0.0293 \\
\hline Age, years & $67(6 I-74)$ & $68(64-74)$ & 0.2767 \\
\hline BMI, kg/m² & $24.4(20.9-27.7)$ & $23.3(19.7-26.9)$ & 0.0785 \\
\hline Pack-years & $48.0(33.5-63.8)$ & $52.5(35.3-66.0)$ & 0.3518 \\
\hline Current smoking (\%) & $99(40.6)$ & $26(47.3)$ & 0.3629 \\
\hline ICS (\%) & $197(80.4)$ & 49 (89.1) & 0.1299 \\
\hline $\mathrm{FEV}_{1}, \mathrm{~L}$ & $1.18(0.86-3.93)$ & $1.70(0.83-2.86)$ & 0.7632 \\
\hline $\mathrm{FEV}_{1}, \%$ pred & $43(34-58)$ & $4 I(33-56)$ & $0.446 I$ \\
\hline $\mathrm{DL}, \mathrm{co}, \mathrm{mmol} / \mathrm{min} / \mathrm{Kpa}$ & $3.9(3.0-9.6)$ & $3.6(2.7-7.7)$ & 0.4038 \\
\hline DL,co, \% pred & 47 (37-59) & $42(32-58)$ & 0.1618 \\
\hline GOLD I/2/3/4, \% & $5.7 / 33.1 / 44.5 / 16.7$ & $5.5 / 27.3 / 50.9 / 16.4$ & 0.8291 \\
\hline GOLD assessment $A / B / C / D, \%$ & $3.7 / 22.5 / 4.9 / 69.0$ & $5.5 / 16.4 / 7.3 / 70.9$ & 0.6515 \\
\hline$\geq 2$ exacerbations/year (\%) & $102(4 \mid .6)$ & $28(50.9)$ & 0.2096 \\
\hline Vitamin $D, \mu g / L^{a}$ & I8.| (12.4-24.8) & $16.2(\mid 2.4-21.2)$ & 0.2057 \\
\hline Vitamin $\mathrm{D} \leq 20 \mu \mathrm{g} / \mathrm{L}(\%)^{\mathrm{a}}$ & I I 2 (56.9) & $30(69.8)$ & 0.1185 \\
\hline A fum $\mathrm{lgG}, \mathrm{mg} / \mathrm{L}$ & $27.7(13.9-44.4)$ & $43.2(27.0-66.0)$ & $<\mathbf{0 . 0 0 0 1}$ \\
\hline Modified Reiff score $\geq 2(\%)$ & $74(30.2)$ & $25(45.5)$ & 0.0297 \\
\hline Sputum PPM (\%) & $94(59.5)$ & $30(76.9)$ & 0.0436 \\
\hline
\end{tabular}

Notes: Data are presented as n (\%), median (interquartile range) or \%. aBased on 240 COPD patients after exclusion of subjects taking vitamin D supplements: 197 non-sensitized and 43 sensitized patients. ${ }^{b}$ Based on 197 patients of whom sputum results were available: 158 non-sensitized and 39 sensitized patients. $P$-values $<0.05$ are shown in bold. Abbreviations: COPD, chronic obstructive pulmonary disease; A fum, Aspergillus fumigatus; BMI, body mass index; ICS, inhaled corticosteroids; $\mathrm{FEV}$, , forced expiratory volume in I second; \% pred, percentage predicted; DL,co, diffusion capacity of the lung for carbon monoxide; GOLD, Global Initiative for Chronic Obstructive Lung Disease; PPM, potential pathogenic microorganisms. 
Table 5 A fum sensitization and bronchiectasis in COPD

\begin{tabular}{llll}
\hline Variables & $\begin{array}{l}\text { COPD } \\
\text { patients (n) }\end{array}$ & $\begin{array}{l}\text { Modified Reiff } \\
\text { score } \geq \mathbf{2}(\%)\end{array}$ & P-values \\
\hline IgE A fum extract & $3 I$ & $12(38.7)$ & 0.4752 \\
$\begin{array}{l}\text { IgE A fum extract or } \\
\text { rAsp fl-f4 and rAsp f6 }\end{array}$ & 55 & $25(45.5)$ & $\mathbf{0 . 0 2 9 7}$ \\
IgE A fum extract & 9 & $0(0)$ & \\
$\begin{array}{l}\text { without recombinants } \\
\text { IgE rAsp fl }\end{array}$ & 36 & & \\
IgE rAsp f3 & 20 & I8 (50) & $\mathbf{0 . 0 2 0 8}$ \\
\hline
\end{tabular}

Notes: Data are presented as $\mathrm{n}$ and $\mathrm{n}(\%)$. P-values $<0.05$ are shown in bold. Abbreviations: COPD, chronic obstructive pulmonary disease; $A$ fum, Aspergillus fumigatus; $\mathrm{rAsp} \mathrm{fl}, A$ fum recombinant $\mathrm{fl}$; $r$ Asp $\mathrm{f} 2, A$ fum recombinant $\mathrm{f} 2 ; \mathrm{rAsp} \mathrm{f} 3, A$ fum recombinant f3; $r$ Asp f4, A fum recombinant f4; $r$ Asp f6, A fum recombinant $f 6$.

\section{Discussion}

This study shows that sensitization to A fum occurs more frequently in COPD patients compared to smoking controls, particularly when rAsp f1 is taken into account. $A$ fum IgG levels are also significantly higher in the COPD group. A fum-sensitized COPD patients are more often male, with more proteobacteria in previous cultures, and depict a higher risk for bronchiectasis if sensitized to rAsp f1 or rAsp f3. Despite considerably lower vitamin D levels in COPD patients compared to controls, we did not find any relation with sensitization to $A$ fum or bronchiectasis.
In our cohort, $34.3 \%$ of COPD patients had increased levels of total IgE compared to $22 \%$ in the control group. The higher prevalence of increased total $\operatorname{IgE}(47.3 \%)$ reported in another COPD cohort ${ }^{7}$ may be explained by demographical differences, variable inclusion criteria and the use of a lower cutoff for positivity. In terms of sensitization to A fum, we found an $18.3 \%$ prevalence in COPD when taking crude extract and recombinant antigens into account. These results are in line with previously reported data of prevalence between $8.5 \%$ and $16 \% .^{6,7,33,34}$ As these studies are lacking an appropriate control group, our data clearly establish that sensitization to A fum is more common in COPD. We are aware of the younger age in our control group, but a median age difference of only 5 years seems insufficient to explain the higher rate of sensitization in COPD. The lack of skin prick tests is a limitation of our study because of a potential discordance between in vitro tests and skin prick tests to diagnose $A$ fum sensitization. ${ }^{35}$

Bafadhel et $\mathrm{al}^{6}$ showed an association between sensitization and lower $\mathrm{FEV}_{1}$ in COPD. Although our sample size was twice as large, we could not observe any relationship with $\mathrm{FEV}_{1}$, diffusion capacity, exacerbations or GOLD stages. A more pronounced male predominance in the sensitized group may seem surprising, but

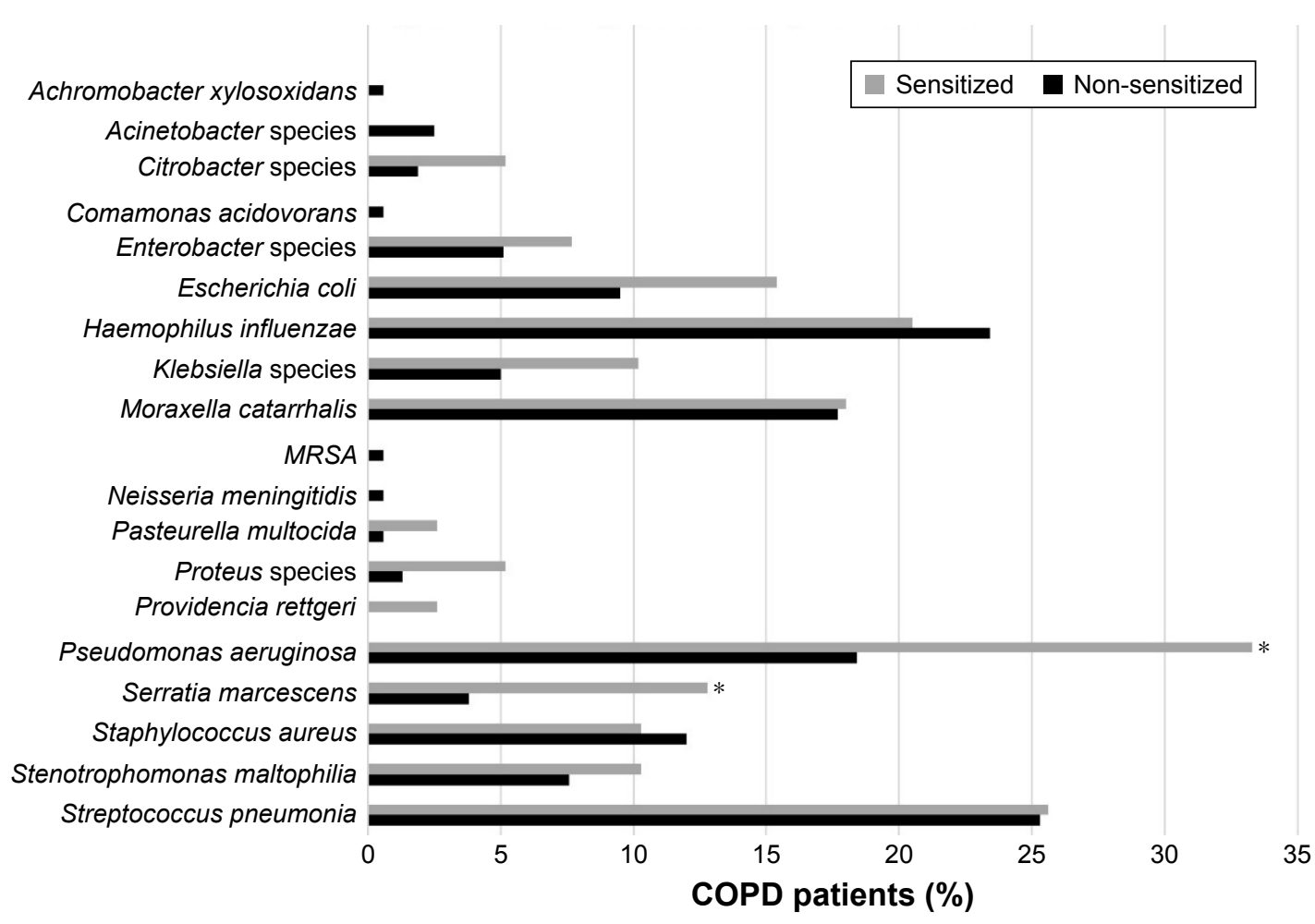

Figure 2 Potential pathogenic microorganisms present in sputum samples of COPD patients by $A$ fum sensitization status. Notes: Occurrence of different species in sputum cultures. $* P<0.05$.

Abbreviations: COPD, chronic obstructive pulmonary disease; A fum, Aspergillus fumigatus; MRSA, methicillin-resistant Staphylococcus aureus. 
Table 6 Association of bronchiectasis (modified Reiff score $\geq 2$ ) and sensitization to rAsp $\mathrm{fl}$ or rAsp $\mathrm{f3}$ in COPD by a logistic regression model

\begin{tabular}{|c|c|c|c|c|}
\hline \multirow[t]{2}{*}{ Variables } & \multicolumn{2}{|c|}{ In all COPD patients $(n=300)$} & \multicolumn{2}{|c|}{$\begin{array}{l}\text { In COPD patients with sputum } \\
\text { samples }(n=197)\end{array}$} \\
\hline & OR (95\% CI) & $P$-values & OR (95\% Cl) & $P$-values \\
\hline Sensitization to $\mathrm{rAsp} \mathrm{fl}$ or $\mathrm{rAsp} \mathrm{f} 3$ & $2.8(1.42-5.53)$ & 0.0030 & $3.4(1.56-7.48)$ & 0.0021 \\
\hline Gender & $\mathrm{I} .5(0.8 \mathrm{I}-2.75)$ & 0.1953 & $1.8(0.82-4.04)$ & 0.1424 \\
\hline Age & $1.0(1.00-1.07)$ & 0.0349 & $1.03(0.99-1.07)$ & 0.2064 \\
\hline BMI & $\mathrm{I} .0(0.9 \mathrm{I}-\mathrm{I} .0 \mathrm{I})$ & 0.1198 & $0.96(0.89-1.03)$ & 0.2155 \\
\hline DL,co, \% pred & $1.0(0.97-1.00)$ & 0.1353 & $0.98(0.96-1.01)$ & 0.1572 \\
\hline$\geq 2$ exacerbations/year & $1.6(0.97-2.72)$ & 0.0642 & $2.11(1.13-3.94)$ & 0.0188 \\
\hline PPM in sputum & NA & & $0.68(0.35-1.32)$ & 0.2573 \\
\hline
\end{tabular}

Note: $P$-values $<0.05$ are shown in bold.

Abbreviations: COPD, chronic obstructive pulmonary disease; $\mathrm{rAsp} \mathrm{fl}, \mathrm{A}$ fum recombinant $\mathrm{fl}$; $\mathrm{rAsp} \mathrm{f} 3, \mathrm{~A}$ fum recombinant $\mathrm{f} 3$; OR, odds ratio; $\mathrm{Cl}$, confidence interval; $\mathrm{BMI}$, body mass index; DL,co, diffusion capacity of the lung for carbon monoxide; \% pred, percentage predicted; PPM, potential pathogenic microorganisms; NA, not applicable.

has been described before. ${ }^{36,37}$ Cigarette smoke exposure is known to facilitate development of sensitization, however we found no difference in pack-years and current smoking between A fum sensitized and non-sensitized COPD patients. This is in contrast to a recent paper about bidi smokers where current smoking seemed a risk factor for A fum sensitization, irrespective of the presence of COPD. ${ }^{34}$ Despite similar disease severity, bronchiectasis was significantly more frequent in sensitized patients, particularly when sensitized to rAsp f1 or rAsp f3 (50\% or $60 \%$ prevalence, respectively). Moreover, multivariate analysis showed that the associated risk for bronchiectasis was independent of gender, age, BMI, diffusion capacity, frequent exacerbations and presence of PPM. Together, these observations support the hypothesis that A fum hypersensitivity might contribute to the development of bronchiectasis in COPD. Based on our results, we are not able to attribute causality. Furthermore, we realize that the association exists in two directions since the presence of bronchiectasis and COPD is a risk factor for colonization with $A$ fum due to reduced mucociliary clearance and therapy with (inhaled) corticosteroids, antibiotics, etc. Nevertheless, some previous papers also suggested $A$ fum as a causal factor for bronchiectasis. Clinically, colonization by $A$ fum was associated with severity of bronchiectasis ${ }^{38}$ and development of bronchiolitis obliterans syndrome after lung transplantation. ${ }^{39}$ Furthermore, A fum sensitization was associated with bronchiectasis, irrespective of ABPA in asthma ${ }^{40}$ and total $\mathrm{IgE}$, which may represent an indirect marker of sensitization, seemed a risk factor for bronchiectasis in COPD patients. ${ }^{41}$ From a mechanistic perspective, Aspergillus proteases play an important role. The serine protease activity of $A$ fum stimulates MUC5AC, resulting in more mucus production by epithelial cells, ${ }^{42}$ and $A$ fum allergen proteases Asp f3 and Asp f15 have been shown to be responsible for the stimulation of the Th2 pathway and airway remodeling in a murine model. ${ }^{43}$

We could not measure blood eosinophils on the frozen blood samples, and therefore, we could not fulfill criteria for ABPA in this cohort. ${ }^{44}$ In a recent paper, A fum $\mathrm{IgG}>27 \mathrm{mg} / \mathrm{L}$ was used in a cohort of sensitized asthma patients to distinguish patients having ABPA from patients without ABPA. ${ }^{45}$ This cutoff seems inappropriate in our $A$ fum-sensitized COPD patients because the median A fum $\mathrm{IgG}$ value in our sensitized group was $43.2 \mathrm{mg} / \mathrm{L}$. This could be explained by the fact that specific IgG is dependent on region, exposure and underlying disease. The higher levels of A fum-specific IgG, as a measure of exposure, may be due to reduced mucociliary function and reduced $A$ fum clearance by innate immune cells in COPD patients versus controls. ${ }^{46}$ This reduced clearance of fungal allergens may facilitate sensitization.

Next to the higher prevalence of bronchiectasis, more A fum-sensitized COPD patients had $P$. aeruginosa and $S$. marcescens present in their sputum compared to A fum-nonsensitized COPD patients. This finding further emphasizes the clinical relevance of our results since these pathogens may play a role in exacerbations and can become multidrug resistant. We did not report on culture results of $A$ fum because the specific growth medium (Sabouraud) was only used on clinical indication. Moreover, sensitivity of culture for $A$ fum is low and other detection methods such as polymerase chain reaction (PCR) may better reflect the presence of $A$ fum in the airways. ${ }^{47}$ Further prospective studies are therefore needed to explore the relationship between $A$ fum colonization, sensitization and bronchiectasis. In line with these unknowns is the potential role of $A$ fum on vitamin D receptor downregulation ${ }^{20}$ as well as the effect of vitamin D deficiency on $A$ fum sensitization ${ }^{19,21}$ and disease severity in bronchiectasis. ${ }^{22}$ Our results did not show any obvious 
relationship, but it is clear that we cannot rule out a role of vitamin D deficiency based on this cross-sectional analysis with a relatively small sample size.

We are the first to report data on IgE against recombinant $A$ fum allergens in COPD. rAsp $\mathrm{fl}$ is a major and speciesspecific allergen of $A$ fum, which in contrast to $A$ fum extract shows no cross-reactivity with proteins of other species. ${ }^{8}$ Exposure to rAsp f1 only occurs during fungal growth, which makes rAsp f1 a reliable and relevant antigen. ${ }^{48}$ Although testing with the crude extract is assumed to be more sensitive than testing with the recombinants, we showed a higher prevalence of sensitization to $\mathrm{rAsp} \mathrm{fl}$ compared to the crude extract. This finding questions the reliability of the crude extract to diagnose $A$ fum sensitization and emphasizes its known limitations such as cross-reactivity, lability and lack of standardization. However, it remains unclear why sensitization to rAsp $\mathrm{f} 2$ and rAsp $\mathrm{f} 3$ (other major allergens of $A$ fum) was less frequently detected. Several reasons could explain why bronchiectasis was not present in the patients only sensitized against the crude $A$ fum extract. The nine patients only sensitized to the crude $A$ fum extract may be false positive due to cross-reactivity. On the other hand, specific allergens may be required to trigger pathways that contribute to bronchiectasis development, although controversial in ABPA. ${ }^{10,49}$ The role of different $A$ fum allergens in the pathogenesis of ABPA and bronchiectasis is far from understood, and $>25$ distinct $A$ fum allergens have been identified.

The prevalence of bronchiectasis in our cohort (33\%) lies within the wide range reported in other studies (4\%-60\%). ${ }^{15,50,51}$ Although there is no specific radiologic scoring system validated for bronchiectasis in COPD, the modified Reiff score, which we applied, has been used in several studies. ${ }^{29,52,53}$ Nevertheless, overestimation of bronchiectasis in COPD is possible since limited bronchiectasis is seen on high-resolution CT scans of healthy individuals and is also related to lung aging. ${ }^{30,54} \mathrm{We}$ tried to avoid overestimation by considering only a modified Reiff score of $\geq 2$ as meaningful and showed that the prevalence of bronchiectasis was at least higher in our patient cohort than in the controls.

\section{Conclusion}

The results show a high prevalence of $A$ fum sensitization in COPD patients and highlight a potential role of rAsp f1 and rAsp $\mathrm{f} 3$ in COPD-related bronchiectasis. Because of the retrospective, observational design of this study, we were not able to demonstrate a causal relationship. Nevertheless, this is the first report about the association between $A$ fum sensitization, including five recombinant antigens, and bronchiectasis in COPD. An association between $A$ fum sensitization and vitamin D deficiency was not found. The search for underlying mechanisms in the development of bronchiectasis in COPD is relevant, since the presence of bronchiectasis in COPD influences management and prognosis of the disease. Prospective, longitudinal studies are needed to prove causality and to allow speculation about preventive interventions.

\section{Acknowledgments}

This study was supported by KU Leuven Research Fund (C24/15/030) and the AstraZeneca Chair KU Leuven. SE is supported as a doctoral candidate by the Fund for Scientific Research Flanders (FWO). KV is supported by the Flemish Government Agency for Innovation by Science and Technology (IWT). LJD and WJ are supported as postdoctoral clinical researchers by the Fund for Scientific Research Flanders (FWO).

\section{Author contributions}

SE contributed to data collection. KL, NL, KV, LJD, BMV and WJ contributed substantially to data interpretation. AD contributed to radiologic interpretations. EVH and XB were responsible for laboratory analysis. $\mathrm{WJ}$ took responsibility for the content of the manuscript and provided the study idea. All authors contributed toward data analysis, drafting and critically revising the paper, gave final approval of the version to be published, and agree to be accountable for all aspects of the work.

\section{Disclosure}

The authors report no conflicts of interest in this work.

\section{References}

1. Barnes PJ, Burney PG, Silverman EK, et al. Chronic obstructive pulmonary disease. Nat Rev Dis Primers. 2015;1:15076.

2. Vogelmeier CF, Criner GJ, Martinez FJ, et al. Global strategy for the diagnosis, management, and prevention of chronic obstructive lung disease 2017 report. GOLD executive summary. Am J Respir Crit Care Med. 2017;195(5):557-582.

3. Han MK, Agusti A, Calverley PM, et al. Chronic obstructive pulmonary disease phenotypes: the future of COPD. Am J Respir Crit Care Med. 2010; 182(5):598-604.

4. Barker BL, Brightling CE. Phenotyping the heterogeneity of chronic obstructive pulmonary disease. Clin Sci. 2013;124(6):371-387.

5. Jamieson DB, Matsui EC, Belli A, et al. Effects of allergic phenotype on respiratory symptoms and exacerbations in patients with chronic obstructive pulmonary disease. Am J Respir Crit Care Med. 2013;188(2):187-192.

6. Bafadhel M, Mckenna S, Agbetile J, et al. Aspergillus fumigatus during stable state and exacerbations of COPD. Eur Respir J. 2014;43(1):64-71.

7. Jin J, Liu X, Sun Y. The prevalence of increased serum IgE and Aspergillus sensitization in patients with COPD and their association with symptoms and lung function. Respir Res. 2014;15(1):130.

8. Crameri R. The problem of cross-reactivity in the diagnosis of fungal allergy. Clin Exp Allergy. 2011;41(3):302-304. 
9. Hemmann S, Menz G, Ismail C, Blaser K, Crameri R. Skin test reactivity to 2 recombinant Aspergillus fumigatus allergens in A. fumigatussensitized asthmatic subjects allows diagnostic separation of allergic bronchopulmonary aspergillosis from fungal sensitization. J Allergy Clin Immunol. 1999;104(3 pt 1):601-607.

10. Knutsen AP, Hutcheson PS, Slavin RG, Kurup VP. IgE antibody to Aspergillus fumigatus recombinant allergens in cystic fibrosis patients with allergic bronchopulmonary aspergillosis. Allergy. 2004;59(2): 198-203.

11. Hurst JR, Elborn JS, Soyza AD. COPD-bronchiectasis overlap syndrome. Eur Respir J. 2015;45(2):310-313.

12. Patel IS, Vlahos I, Wilkinson TM, et al. Bronchiectasis, exacerbation indices, and inflammation in chronic obstructive pulmonary disease. Am J Respir Crit Care Med. 2004;170(4):400-407.

13. Gatheral T, Kumar N, Sansom B, et al. COPD-related bronchiectasis; independent impact on disease course and outcomes. COPD. 2014; 11(6):605-614.

14. Du Q, Jin J, Liu X, Sun Y. Bronchiectasis as a comorbidity of chronic obstructive pulmonary disease: a systematic review and meta-analysis. PLoS One. 2016;11(3):e0150532.

15. Martínez-García M-A, de la Rosa Carrillo D, Soler-Cataluña J-J, et al. Prognostic value of bronchiectasis in patients with moderate-to-severe chronic obstructive pulmonary disease. Am J Respir Crit Care Med. 2013;187(8):823-831.

16. McDonnell MJ, Aliberti S, Goeminne PC, et al. Comorbidities and the risk of mortality in patients with bronchiectasis: an international multicentre cohort study. Lancet Respir Med. 2016;4(12):969-979.

17. Cole PJ. Inflammation: a two-edged sword - the model of bronchiectasis Eur J Respir Dis Suppl. 1986;147:6-15.

18. De Soyza A, Aliberti S. Bronchiectasis and Aspergillus: how are they linked? Med Mycol. 2016;55(1):69-81.

19. Kreindler JL, Steele C, Nguyen N, et al. Vitamin D3 attenuates Th2 responses to Aspergillus fumigatus mounted by CD4+ T cells from cystic fibrosis patients with allergic bronchopulmonary aspergillosis J Clin Invest. 2010;120(9):3242-3254.

20. Coughlan CA, Chotirmall SH, Renwick J, et al. The effect of Aspergillus fumigatus infection on vitamin D receptor expression in cystic fibrosis. Am J Respir Crit Care Med. 2012;186(10):999-1007.

21. Li P, Xu X, Cao E, et al. Vitamin D deficiency causes defective resistance to Aspergillus fumigatus in mice via aggravated and sustained inflammation. PLoS One. 2014;9(6):e99805

22. Chalmers JD, McHugh BJ, Docherty C, Govan JR, Hill AT. Vitamin-D deficiency is associated with chronic bacterial colonisation and disease severity in bronchiectasis. Thorax. 2013;68(1):39-47.

23. Janssens W, Bouillon R, Claes B, et al. Vitamin D deficiency is highly prevalent in COPD and correlates with variants in the vitamin D-binding gene. Thorax. 2010;65(3):215-220.

24. Bestall JC, Paul EA, Garrod R, Garnham R, Jones PW, Wedzicha JA. Usefulness of the medical research council (MRC) dyspnoea scale as a measure of disability in patients with chronic obstructive pulmonary disease. Thorax. 1999;54(7):581-586.

25. van Iersel CA, de Koning HJ, Draisma G, et al. Risk-based selection from the general population in a screening trial: selection criteria, recruitment and power for the Dutch-Belgian randomised lung cancer multi-slice CT screening trial (NELSON). Int J Cancer. 2007;120(4):868-874.

26. Miller MR, Hankinson J, Brusasco V, et al; ATS/ERS Task Force. Standardisation of spirometry. Eur Respir J. 2005;26(2):319-338.

27. Rosenberg E. The 1995 update of recommendations for a standard technique for measuring the single-breath carbon monoxide diffusing capacity (transfer factor). Am J Respir Crit Care Med. 1996;154(3 pt 1): 827-828.

28. Naidich DP, McCauley DI, Khouri NF, Stitik FP, Siegelman SS. Computed tomography of bronchiectasis. J Comput Assist Tomogr. 1982;6(3):437-444.

29. Chalmers JD, Goeminne P, Aliberti S, et al. The bronchiectasis severity index. An international derivation and validation study. Am J Respir Crit Care Med. 2014;189(5):576-585.
30. Lynch DA, Newell JD, Tschomper BA, Cink TM, Newman LS, Bethel R. Uncomplicated asthma in adults: comparison of CT appearance of the lungs in asthmatic and healthy subjects. Radiology. 1993; 188(3):829-833.

31. Zetterström O, Johansson SG. IgE concentrations measured by PRIST in serum of healthy adults and in patients with respiratory allergy. A diagnostic approach. Allergy. 1981;36(8):537-547.

32. Global Initiative for Chronic Obstructive Lung Disease [homepage on the Internet]. From the Global Strategy for the Diagnosis, Management and Prevention of COPD. Global Initiative for Chronic Obstructive Lung Disease (GOLD); 2017. Available from: http://goldcopd.org. Accessed July 6, 2017.

33. Agarwal R, Hazarika B, Gupta D, Aggarwal AN, Chakrabarti A, Jindal SK. Aspergillus hypersensitivity in patients with chronic obstructive pulmonary disease: COPD as a risk factor for ABPA? Med Mycol. 2010; 48(7):988-994.

34. Agarwal R, Bhogal S, Choudhary H, et al. Aspergillus sensitisation in bidi smokers with and without chronic obstructive lung disease. Mycoses. 2017;60(6):381-386.

35. Kespohl S, Maryska S, Bünger J, et al. How to diagnose mould allergy? Comparison of skin prick tests with specific IgE results. Clin Exp Allergy. 2016;46(7):981-991.

36. Mari A, Schneider P, Wally V, Breitenbach M, Simon-Nobbe B. Sensitization to fungi: epidemiology, comparative skin tests, and IgE reactivity of fungal extracts. Clin Exp Allergy. 2003;33(10):1429-1438.

37. Fattahi F, ten Hacken NH, Löfdahl CG, et al. Atopy is a risk factor for respiratory symptoms in COPD patients: results from the EUROSCOP study. Respir Res. 2013;14(1):10.

38. Máiz L, Vendrell M, Olveira C, Girón R, Nieto R, Martínez-García MÁ. Prevalence and factors associated with isolation of Aspergillus and Candida from sputum in patients with non-cystic fibrosis bronchiectasis. Respiration. 2015;89(5):396-403.

39. Weigt SS, Copeland CAF, Derhovanessian A, et al. Colonization with small conidia Aspergillus species is associated with bronchiolitis obliterans syndrome: a two-center validation study: Aspergillus conidia size and risk of BOS. Am J Transplant. 2013;13(4):919-927.

40. Woolnough KF, Richardson M, Newby C, et al. The relationship between biomarkers of fungal allergy and lung damage in asthma. Clin Exp Allergy. 2017;47(1):48-56.

41. Jin J, Yu W, Li S, Lu L, Liu X, Sun Y. Factors associated with bronchiectasis in patients with moderate-severe chronic obstructive pulmonary disease. Medicine (Baltimore). 2016;95(29):e4219.

42. Oguma T, Asano K, Tomomatsu K, et al. Induction of mucin and MUC5AC expression by the protease activity of Aspergillus fumigatus in airway epithelial cells. J Immunol. 2011;187(2):999-1005.

43. Namvar S, Warn P, Farnell E, et al. Aspergillus fumigatus proteases, Asp f 5 and Asp f 13, are essential for airway inflammation and remodelling in a murine inhalation model. Clin Exp Allergy. 2015;45(5): 982-993.

44. Agarwal R, Chakrabarti A, Shah A, et al; ABPA complicating asthma ISHAM working group. Allergic bronchopulmonary aspergillosis: review of literature and proposal of new diagnostic and classification criteria. Clin Exp Allergy. 2013;43(8):850-873.

45. Agarwal R, Dua D, Choudhary H, et al. Role of Aspergillus fumigatusspecific IgG in diagnosis and monitoring treatment response in allergic bronchopulmonary aspergillosis. Mycoses. 2017;60(1):33-39.

46. Barnes PJ. Inflammatory mechanisms in patients with chronic obstructive pulmonary disease. J Allergy Clin Immunol. 2016;138(1):16-27.

47. Baxter CG, Dunn G, Jones AM, et al. Novel immunologic classification of aspergillosis in adult cystic fibrosis. J Allergy Clin Immunol. 2013; 132(3):560-566.e10.

48. Fukutomi Y, Taniguchi M. Sensitization to fungal allergens: resolved and unresolved issues. Allergol Int. 2015;64(4):321-331.

49. Jolink H, de Boer R, Willems LN, van Dissel JT, Falkenburg JH, Heemskerk MH. T helper 2 response in allergic bronchopulmonary aspergillosis is not driven by specific Aspergillus antigens. Allergy. 2015; 70(10):1336-1339. 
50. Agusti A, Calverley PM, Celli B, et al; Evaluation of COPD Longitudinally to Identify Predictive Surrogate Endpoints (ECLIPSE) investigators. Characterisation of COPD heterogeneity in the ECLIPSE cohort. Respir Res. 2010;11(1):122.

51. Bafadhel M, Umar I, Gupta S, et al. The role of CT scanning in multidimensional phenotyping of COPD. Chest. 2011;140(3):634-642.

52. Reiff DB, Wells AU, Carr DH, Cole PJ, Hansell DM. CT findings in bronchiectasis: limited value in distinguishing between idiopathic and specific types. AJR Am J Roentgenol. 1995;165(2):261-267.
53. Pasteur MC, Helliwell SM, Houghton SJ, et al. An investigation into causative factors in patients with bronchiectasis. Am J Respir Crit Care Med. 2000;162(4 pt 1):1277-1284.

54. Quint JK, Millett ER, Joshi M, et al. Changes in the incidence, prevalence and mortality of bronchiectasis in the UK from 2004 to 2013: a population-based cohort study. Eur Respir J. 2016;47(1):186-193.

\section{Publish your work in this journal}

The International Journal of COPD is an international, peer-reviewed journal of therapeutics and pharmacology focusing on concise rapid reporting of clinical studies and reviews in COPD. Special focus is given to the pathophysiological processes underlying the disease, intervention programs, patient focused education, and self management protocols.

\section{Dovepress}

This journal is indexed on PubMed Central, MedLine and CAS. The manuscript management system is completely online and includes a very quick and fair peer-review system, which is all easy to use. Visit $\mathrm{http}: / / \mathrm{www}$.dovepress.com/testimonials.php to read real quotes from published authors. 